\title{
ABetaA21G amyloidosis
}

INSERM

\section{Source}

INSERM. (1999). Orphanet: an online rare disease and orphan drug data base.

ABetaA21G amyloidosis. ORPHA:324718

Hereditary cerebral hemorrhage with amyloidosis (HCHWA), Flemish type is a form of HCHWA (see this term) characterized by an age of onset of 45 years of age, progressive Alzheimer's disease-like dementia and lobar intracerebral hemorrhage in some patients. 